Original Research Paper

\title{
A new Framework of Strategic Human Resource Management (SHRM) Based on Quantitative and Qualitative Data
}

\author{
Rachid Belhaj and Mohamed Tkiouat \\ Mohammadia School of Engineering Rabat, Studies and Research Laboratory in Applied Mathematics (LERMA), \\ Mohammed V University, Agdal, Morocco
}

Article history

Received: 30-08-2016

Revised: $23-10-2016$

Accepted: 14-02-2017

Corresponding Author:

Rachid Belhaj

Mohammadia School of

Engineering Rabat, Studies and

Research Laboratory in

Applied Mathematics

(LERMA), Mohammed V

University, Agdal, Morocco

Email: rachidblh@yahoo.fr

\begin{abstract}
Strategic Human Resource Management (SHRM) is a new concept followed especially in private sector; it is an approach to managing human resource that supports long-term business goals, it tries to enhance the management of HR to a strategic level through human capital. The purpose of this paper is to shed light on the main concepts used in the strategic human resource management, including the management and planning of human resource and focusing on the strategy formulation steps to arrive to a general framework of the SHRM. The present study was performed after analysing the SHRM formulation steps and proposing the process of implementation in the public and private sectors, the proposed framework suggests the use of scientific tools such as Markov modelling for the HR supply forecasting and the fuzzy method to refine the choice of a suitable strategy among others. The main finding of the paper is the proposition of a framework of SHRM that relies on quantitative and qualitative data, which enable us to rely on well analysed information to build a strategy. The reason behind this is to emphasize and encourage the use of scientific models in order to approach the reality and to refine the future projections.
\end{abstract}

Keywords: Strategic Human Resource Management, Strategy Implementation, SWOT Analysis, Fuzzy Method

\section{Introduction}

Human Resource (HR) takes a dominated place in the life of an organization knowing that it becomes one of the competitive factors; it is also considered an important preoccupation for governments that try to control the wage bill and the HR structure evolution.

The human capital is the resource that consists of the people who work to achieve the mission and ambition of an organization and ensure its business success; in that context Afiouni (2013) has been interested in understanding the complexity of managing human capital, Yusoff and Ramayah (2012) proposed a study to this problem consisting of the use of the e-HRM.

First let's begin by defining what a strategy is. In sample words, strategy is defining what is wanted to be done and how to do it. Armstong (2006) has defined it as a declaration of intent which concerns longer term goals; it is more concerned with how those goals should be achieved.
Strategy has been defined in other ways by many writers on this subject, for example:

"A strategy, whether it is an HR strategy or
any other kind of management Strategy must
have two key elements: There must be
strategic objectives (i.e., things the strategy is
supposed to achieve) and there must be a plan
of action (i.e., the means by which it is
proposed that the objectives will be
met)."(Richardson and Thompson (1999))

For a long time; strategies making have been kept away from the HR field, it has concerned in the first place trade, industries, investment or the business in general. Recently it has been emphasized that HRM is strategic by nature. Pynes (2004) has been interested by SHRM, he believed that to stand up with concurrence and the world business changes organizations need realistic information about their HR. in that sense he supported that SHRM is the implementation of HR 
policies and practices in order to make the necessary changes to meet the organization's strategic objectives.

Other definition is given by Pinnamaneni et al. (2015) who made lights about linking the organization's HR practices to its strategy and so did Wright and McMahan (1992) who mentioned the deployment of planed HR to enable the firm to achieve its goals.

Additionally to what have been said above, it is noted that the trend in HRM is to enhance it to a strategic level. Pinnamaneni et al. (2015) argues that SHRM is used to gain competitive advantage; it tries to enhance HRM to the business strategy level. It is well known now the relationship between HRM practices and innovation; (Seeck and Diehl, 2016). In the same context Amarakoon et al. (2016) studied how such innovations support competitive advantage whereas Kaufman (2015) clarified the implications concerning HRM and performance.

For decades organisations wait from their HRM practices just to meet the short term requirements of their missions, now with the entering of the SHRM in the schedule of the decision makers, organizations are better able to respond to the demand of their internal and external environment.

For now on SHRM is a part of the process of strategies formulation (Pynes, 2004).

\section{Materials and Methods}

\section{Strategic Management Process}

During strategy setting, human resource managers take part in the formulation of the strategic plan; there is an increased conscience that human resource planners have a major role in the strategic management.

The strategy plan determines organizational purposes and objectives and also the way and resources to achieve it. According to Wayne Mondy and Martocchio (2016) there are four steps to formulate a strategy, Fig. 1:

- Step 1: Mission determination; it is deciding what is the general purpose of the organization

- Step 2: Environmental assessment, it concerns the environmental scanning, from evaluating internal strengths and weaknesses to predicting external opportunities and threats

- Step3: Objective setting; determining the essential objective and lightening general orientations

- Step 4: Strategy setting; assigning a strategy to each objective and specifying how to achieve it

\section{Implementing Strategic Human Resource Management}

Strategic human resource management has taken recently a big importance both in the field of human resource management and in the field of strategic management. For Pinnamaneni et al. (2015) SHRM is based mainly on human capital in achieving the longterm objectives of the company. Miles and Snow (1978) viewed that HRM is the key factor in implementing business strategies; in that sense it must be enhanced to the longer term management level. Crispin et al. (2016) made light on the fact that implementing SHRM can have a positive result on employee's performance.

Figure 2 and 3 shows a detailed SHRM formulation process in private sector and in the public sector. The proposed models take into consideration the latest finding in the field of the strategic management.

Mintzberg (1978) concluded that all strategies come from the mind of people they make an impact upon and in order to achieve this view it is essential that HR in the organization share the same perspective, that's what he called the collective mind.

\section{Human Resources Planning, a Component of SHRM}

\section{Strategic Planning}

Torrington et al. (2005) defined strategic planning as the process of collecting information about HR to meet the organization's objectives; it includes the analysis of the existing HR and the assessment of the availability of new ones in numbers and skills outside. Planning uses the forecast tools to link the past data with the future trends.

Human Resource Planning (HRP) (workforce planning) is a continuous process that tries to fill the empty positions with the internal and external supply. HRP requires knowledge and data coming from the business plan and the statistical analysis.

As it was said the strategic planning precedes the human resources planning. HRP compares HR requirements and availabilities. After analyzing the quantity of surplus and shortage, strategies must be found to deal with each situation.

Succession planning is a way to guarantee the filling of top management positions by recruitment and promotions of the internal employees through regular management training. This type of planning came back strongly in the $2000 \mathrm{~s}$ where organisations have been imposed to have succession schema to collaborate with financial institutions (Stredwick, 2005).

\section{Manpower Planning Models-Traditional Human Resource Planning}

The emphasis in a traditional manpower planning is on knowing the numbers of employees that will be needed in the future according to the existing ones and the manpower supply from the internal and external environment. A typical model of traditional manpower planning is shown in Fig. 4 (Torrington et al., 2005). 


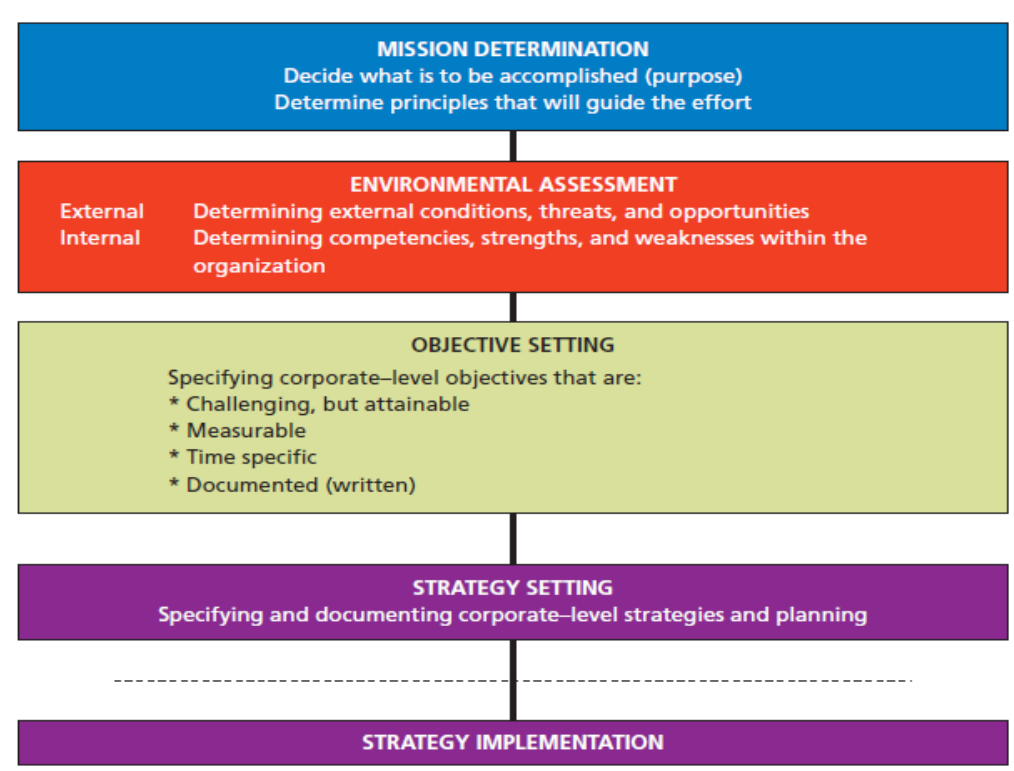

Fig. 1. Strategic management process (Wayne and Martocchio, 2016)

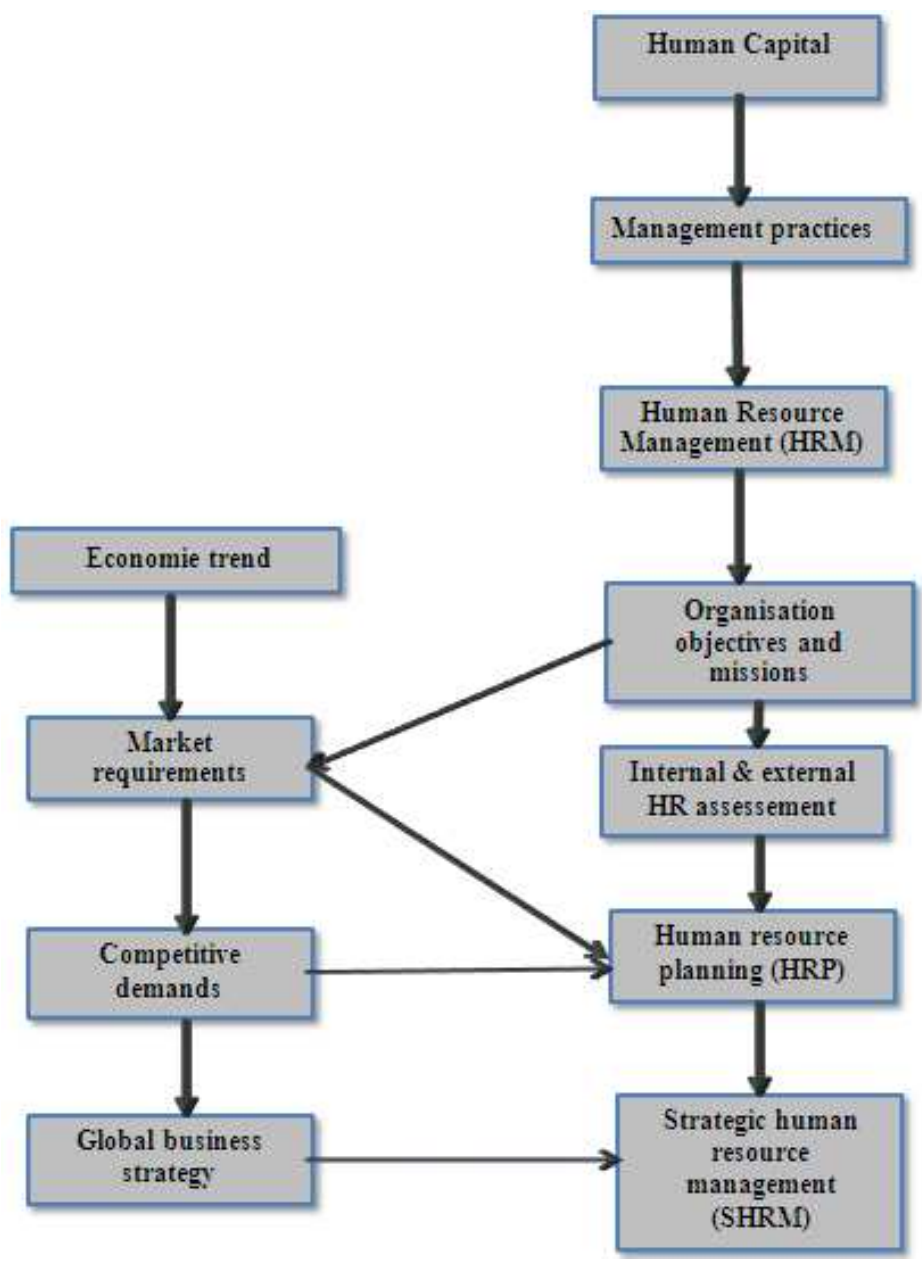

Fig. 2. SHRM formulation process in private sector 


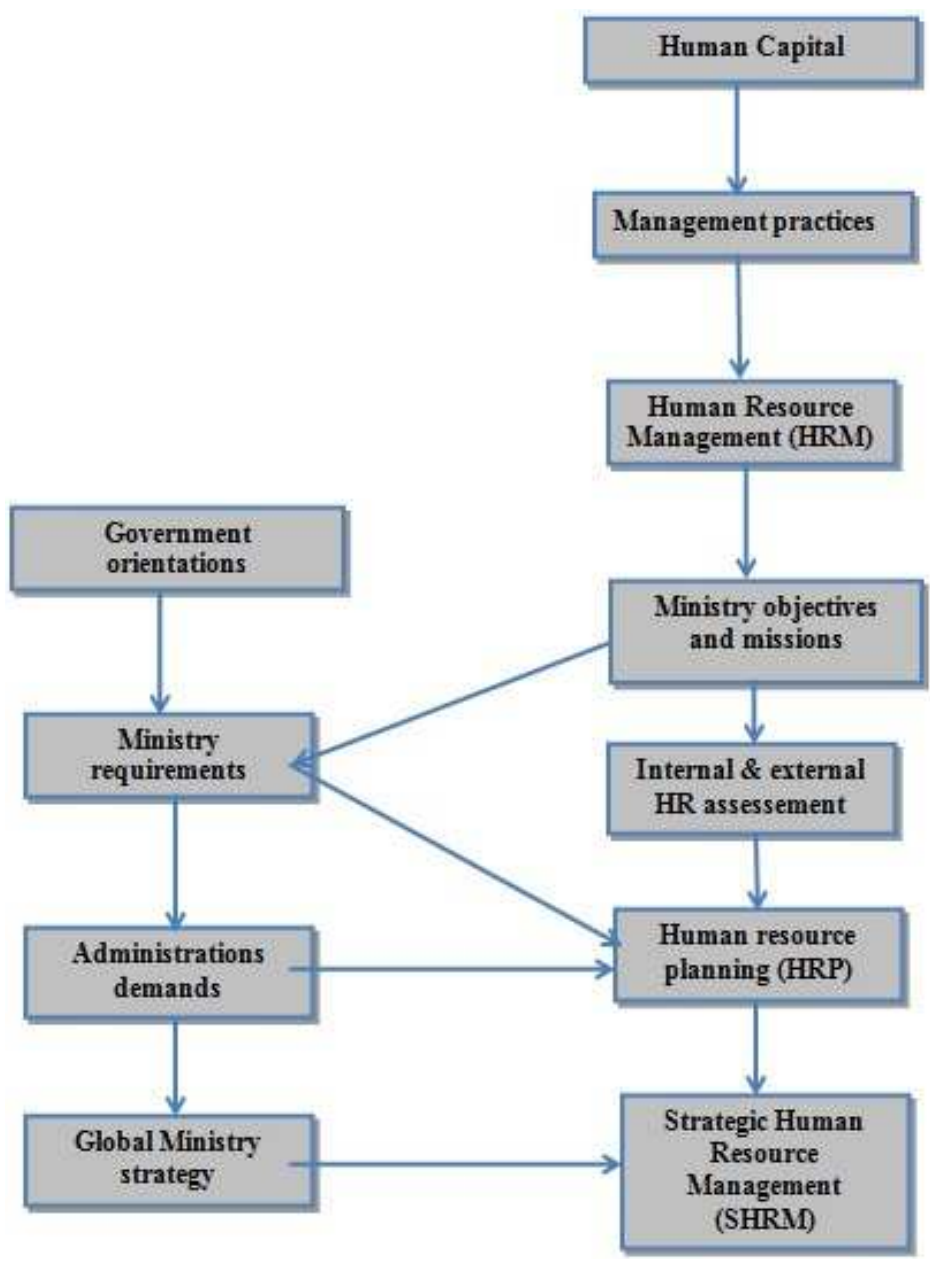

Fig. 3. SHRM formulation process in the public sector. (SHRM in a Ministry)

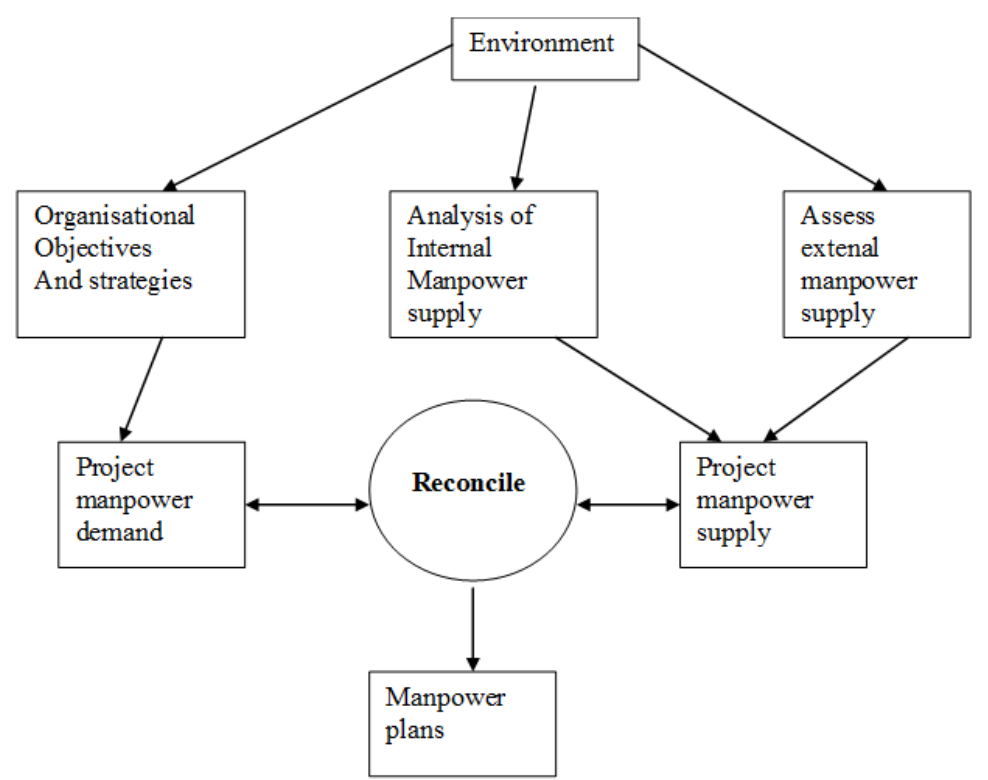

Fig. 4. A model of traditional manpower planning (Torrington et al., 2005) 
To achieve a planning of the human resources in a traditional way, first we begin by an analysis of the corporate strategies and objectives to estimate the future demand (a task performed by the top management).

The supply is influenced by the internal and the external environment:

- Internally, simulations are performed to expect the supply of human resources by taking into consideration the numbers of recruitments, retirements, promotions...etc

- Externally, a study is performed to anticipate the supply of human resources from the labour market. The forecasted demand and supply are then reconciled to arrive to a possible balancing using a plan to achieve it (Torrington et al., 2005)

\section{Results}

\section{A New Approach of Designing a SHRM Framework}

\section{Understanding the Environment}

The authors conclude that HR has to be managed with a strategic vision, which means it has to go with the general strategic business. Hence SHRM plays a decisive role in achieving the vision of the organization by providing the necessary employees and skills.

What differentiates the private sector from the public sector is the way HR is managed. In public sector there are a lot of reforms and every year new government laws and programs, but when talking about the yield it is actually very minim, a legitimate question is to ask why government reforms do not give what they are supposed to give in terms of changes and benefits to the population. The answer is difficult but there is an obvious factor that not everyone understands it, there must be an effective conscience that the HR is the key factor of the success of every reform.

The SHRM begins with developing a common vision of the future, what are the ambitions and future investments of the organization; its business strategy, after that take a look to the actual state of the whole HR system in terms of numbers and competencies then trying to much the HR availability with the desired demand.

\section{The Approach}

The following plan (Fig. 5) gives the proposed steps for a SHRM formulation beginning with the strategic planning; it relies on quantitative and qualitative data to define a HR strategy.

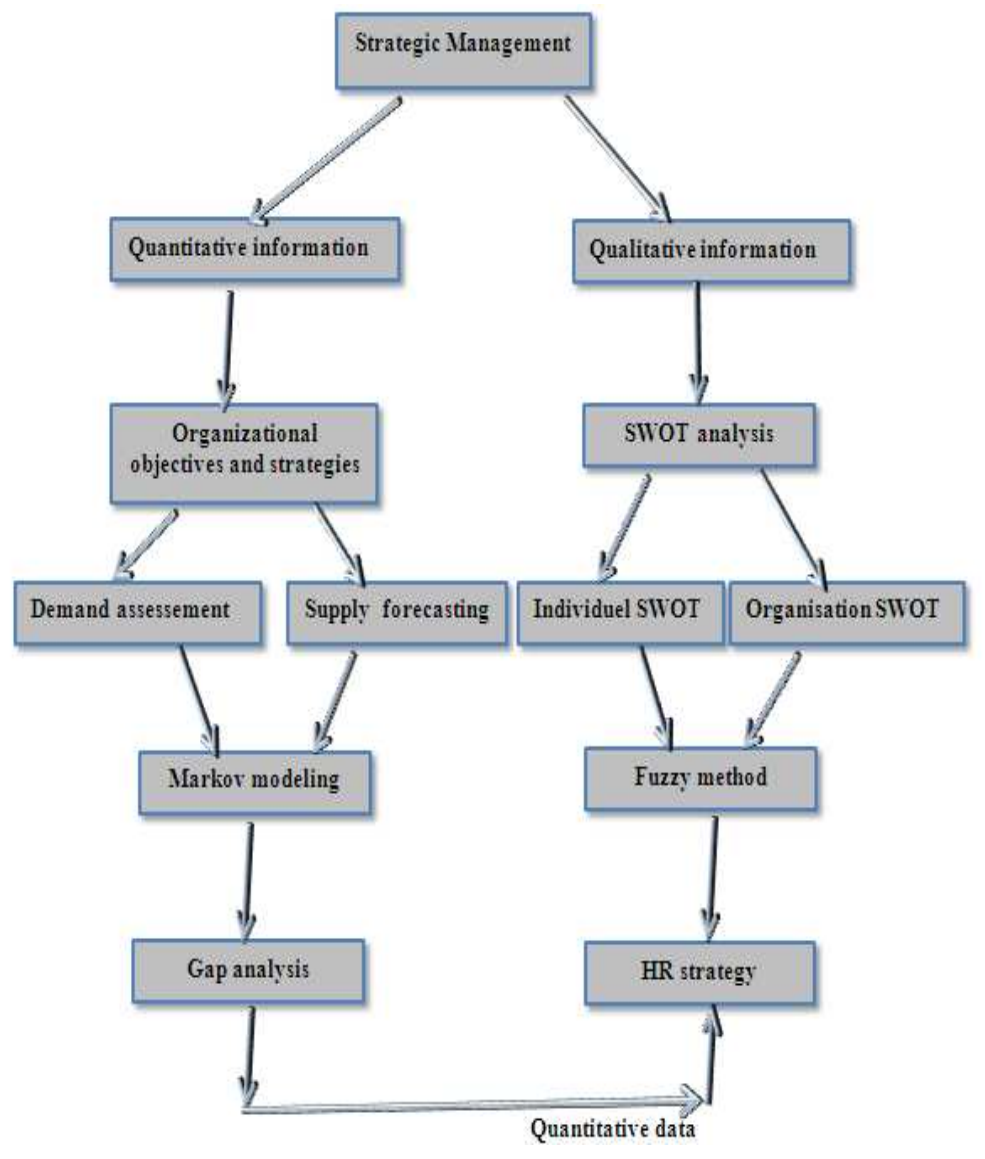

Fig. 5. A general SHRM framework (the HR strategy formulation) 
Quantitative Information comes from the Gap Analysis using Markov Modeling (for Example), (Belhaj and Tkiouat, 2013)

In forecasting the supply of human resources, organizations must consider both internal and external supply of qualified candidates. The domestic supply of candidates is influenced by the training, the manpower development, mobility policies, promotion and retirement. In this step the Markov modeling is one of the best tools to model the manpower structure evolution.

The objective of constructing a stochastic model of the process of human resources is especially to be able to predict future numbers in the different categories of grades. The stochastic model specifies for each process, in probabilistic terms the law of change in each individual level.

Researchers used a Markov model associated or integrated to describe the change of the process in light of its historical evolution, (Bartholomew, 1982). Although these models are formulated in stochastic terms, they are always treated in a discreet way. The current number of individuals in a group of grades is a random variable, but the analysis proceeds by replacing each random variable by its expectation.

The problem of planning is treated by dividing the entire heterogeneous manpower system in several homogeneous subgroups (families of the same grades) which form a partition of the entire personnel system. This simplifies the prediction of the manpower evolution, as it becomes acceptable that everyone in the same group evolves similarly. This model gives a more realistic view of the manpower advancement and the development of each employee in his normal family.

Qualitative Information uses SWOT Analysis Coupled to FUZZY Method (for Example) to Refine the Strategy Adoption, (Belhaj and Tkiouat, 2014)

An augmented SWOT analysis approach is performed to evaluate strategies in the field of the Strategic Human Resources Management (SHRM). The ratings and attractive scores used require judgmental decisions and should be based on expert's opinion to ensure the applicability of the chosen strategies. That's why the fuzzy decision making method is proposed based on building a fuzzy inference system to treat a second time the inputs data (coming from SWOT analysis) by the fuzzy method with the goal of finding a better strategies prioritization.

Fuzzy inference is a process of formulating the mapping of the input data to an output using fuzzy logic. It includes all these episodes: Membership function, fuzzy logic operators and the if-then rules, (Nobari et al., 2012). Fuzzy Inference Systems have successful applications in automatic control, data classification and decision analysis.
The influence of the vagueness data and human feelings express can be especially problematic when most of the data collected during the scoring process are qualitative, (Hosseini-Nasab et al., 2011). A simple fuzzy SWOT approach is suggested to overcoming the problem. Belhaj and Tkiouat (2015) have included the client opinion and employee engagement in the Strategic Human Resource Management by using an advanced SWOT- FUZZY decision making tool.

\section{Discussion}

Several studies have treated the issue of SHRM, Qayed Al-Emadi and Schwabenland (2015) examined traditional and recent studies in order to assert the main concepts of HRM models, a particular attention has been given to the configurational approach which works with quantitative data.

Reeshad and Bolunmez (2016) stated that intelligence and experience are insufficient for effective decision making knowing that $50 \%$ of firms have a failure in decision making, the study proposed to consider the option if having a wrong decision to make.

Studies treating strategy in relation to performance have also been conducted, in this context Uysal (2014) affirmed that SHRM can be defined with employee/firm performance relationship. The author developed a model where HRM practices develop individual performance of employees to impact the general performance of the organization. Waiganjo et al. (2012) developed a framework that shows the influence of HR on the firm performance and so made light on the relation between SHRM and the firm performance.

Decision making in the field of the SHRM cannot be taken just from the conventional methods of management, as it was stated before performance is highly correlated to the way HR are managed. It is time to switch up from the traditional management of HR to a modern and scientific approach that can enable us to manage strategically. The proposed framework tries to emphasize on the importance of integrating scientific tools in the strategic human resource formulation. It is with reliable data and well analyzed information that a strategy can be built.

\section{Conclusion}

Human Resource management has a major impact on individual and so on productivity and organizational performance. Strategic Human Resource Management implies the ways in which HRM is crucial to organizational effectiveness. Hence organizations have to carefully design strategies by using quantitative and qualitative data for effective utilization in achieving greater competitive performance. 
The present paper presents an overview of the SHRM field by making light on the main concepts and steps of the strategy formulation, in the same time models and scientific tools have been used to enhance the HRM to a modern branch of science.

Organizations today are facing new changes in HR policies, in this context there are new challenges that have been identified, beginning by giving more importance to new technological tools in managing HR, thinking strategically about HR, preparing managers and succession plans, giving attention to employee commitment and social climate and exploiting analysis of HR data.

\section{Acknowledgment}

We would like to thank the head of the Studies and Research Laboratory in Applied Mathematics (LERMA) Professor Rajae ABOULAICH for the continuous support and motivation.

\section{Funding Information}

The authors have no support or funding to report.

\section{Author's Contributions}

This study is the result of the full and equal collaboration of all the authors:

Rachid Belhaj: Ideas generation; literature review and proposed the main steps of the SHRM framework.

Mohamed Tkiouat: Developed the concept and the idea, the methodology designing and the framework validation.

\section{Ethics}

This article is original and contains unpublished material. The corresponding author confirms that all of the other authors have read and approved the manuscript and no ethical issues involved.

\section{References}

Afiouni, F., 2013. Human capital management: A new name for HRM? Int. J. Learn. Intell. Capital, 10: 18-34. DOI: 10.1504/ijlic.2013.052081

Amarakoon, U., J. Weerawardena and M.L. Verreynne, 2016. Learning capabilities, human resource management innovation and competitive advantage. Int. J. Human Resource Manage., 1-31-31. DOI: $10.1080 / 09585192.2016 .1209228$

Armstong, M., 2006. Strategic Human Resource Management: A Guide to Action. 3rd Edn., Kogan, ISBN-10: 0749445114, pp: 194.

Bartholomew, D.J., 1982. Stochastic Models for Social Processes. 3rd Edn., Wiley, England, ISBN-10: 0471280402, pp: 365.
Belhaj, R. and M. Tkiouat, 2013. A Markov model for human resources supply forecast dividing the HR system into subgroups. J. Service Sci. Manage., 6: 211-217. DOI: 10.4236/jssm.2013.63023

Belhaj, R. and M. Tkiouat, 2014. Conducting a SWOT analysis with a prioritizing model based on fuzzy inference system, decision support tool in the strategic human resources management. Eur. J. Econom. Finance Admin. Sci., 69: 59-69.

Belhaj, R. and M. Tkiouat, 2015. Including client opinion and employee engagement in the strategic human resource management: An advanced SWOTFUZZY decision making tool. Int. J. Human Capital Inform. Technol. Profess., 6: 20-34. DOI: 10.4018/IJHCITP.2015070102

Crispin, C.C., A. Vasumathi and R. Subashini, 2016. The role of Strategic Human Resource Management (SHRM) impacting employee's performance through perceived organisational support in a manpower agency of international airlines at Chennai International Airport, Tamil Nadu, India - an empirical study. Int. J. Services Operat. Manage., 23: 217-217. DOI: 10.1504/ijsom.2016.074057

Hosseini-Nasab, H., A. Hosseini-Nasab and A.S. Milani, 2011. Coping with Imprecision in strategic planning: A case study using fuzzy SWOT analysis. IBusiness IB, 03: 23-29.

DOI: $10.4236 /$ ib.2011.31004

Kaufman, B.E., 2015. Market competition, HRM and firm performance: The conventional paradigm critiqued and reformulated. Human Resource Manage. Rev., 25: 107-125.

DOI: 10.1016/j.hrmr.2014.08.001

Miles, R.E. and C.C. Snow, 1978. Organizational Strategy, Structure and Process. 1st Edn., McGrawHill, New York, ISBN-10: 0070419329, pp: 274.

Mintzberg, H., 1978. Patterns in strategy formation. Manage. Sci., 24: 934-948.

DOI: $10.1287 / \mathrm{mnsc} .24 .9 .934$

Nobari, S., Z. Jabrailova and A. Nobari, 2012. Using fuzzy decision support systems in human resource management. Proceedings of the International Conference on Innovation and Information Management, (IIM' 12), IACSIT Press, Singapore, pp: 204-207.

Pinnamaneni, N., D. Xu and H. Findley, 2015. Strategic human resource management.

Pynes, J.E., 2004. Human Resources Management for Public and Nonprofit Organizations. 2nd Edn., Jossey-Bass Awiley Imprint, ISBN-10: 0787975575, pp: 400.

Qayed Al-Emadi, A.A. and C. Schwabenland, 2015. An investigation into the SHRM perspectives effectiveness: A comparative study. Int. J. Manage. Bus. Stud., 5: 180-188. 
Reeshad, S.D. and B. Bolunmez, 2016. Evidence-based strategies to improve workplace decisions: Small steps, big effects. SHRM-SIOP Science of HR Series. George Mason University.

Richardson, R. and M. Thompson, 1999. The impact of people management practices on business performance: A literature review. Institute of Personnel and Development, London.

Seeck, H. and M.B. Diehl, 2016. A literature review on HRM and innovation-taking stock and future directions. Int. J. Human Resource Manage., 1-32-32. DOI: $10.1080 / 09585192.2016 .1143862$

Stredwick, J., 2005. An Introduction to Human Resource Management. 2nd Edn., Elsevier ButterworthHeinemann.

Torrington, D., L. Hall and S. Taylor, 2005. Human Resource Management. 6th Edn., Financial Times Prentice Hall, Harlow.

Uysal, G., 2014. Stages, content and theory of Strategic Human Resource Management (SHRM): An exploratory study. J. Modern Account. Audit., 10: 252-256.
Waiganjo, E.W., E. Mukulu and J. Kahiri, 2012. Relationship between strategic human resource management and firm performance of Kenya's corporate organizations. Int. J. Human. Soc. Sci.

Wayne Mondy, R. and J.J. Martocchio, 2016. Human Resource Management. 14th Edn., Global Edition Pearson Education Limited.

Wright, P.M. and G.C. McMahan, 1992. Theoretical perspectives for strategic human resource management. J. Manage., 18: 295-320.

DOI: $10.1177 / 014920639201800205$

Yusoff, Y.M. and T. Ramayah, 2012. Electronic Human Resource Management (e-HRM) and Human Resource (HR) competencies: Some evidence from an emerging market. Int. J. Inform. Commun. Technol., 4: 27-39. DOI: 10.1504/ijict.2012.045746 